$\mathrm{Oz}$

Volume 13

Article 7

$1-1-1991$

\title{
Alchemical Transformation: Building Into Architecture
}

Ellen Dunham-Jones

Jude LeBlanc

Follow this and additional works at: https://newprairiepress.org/oz

(c) (1) $\Theta \Theta$

This work is licensed under a Creative Commons Attribution-Noncommercial-No Derivative Works 4.0 License.

\section{Recommended Citation}

Dunham-Jones, Ellen and LeBlanc, Jude (1991) "Alchemical Transformation: Building Into Architecture," Oz: Vol. 13. https://doi.org/10.4148/2378-5853.1219

This Article is brought to you for free and open access by New Prairie Press. It has been accepted for inclusion in Oz by an authorized administrator of New Prairie Press. For more information, please contact cads@k-state.edu. 


\section{Alchemical Transformation: Building Into Architecture}

Ellen Dunham-Jones

Jude LeBlanc

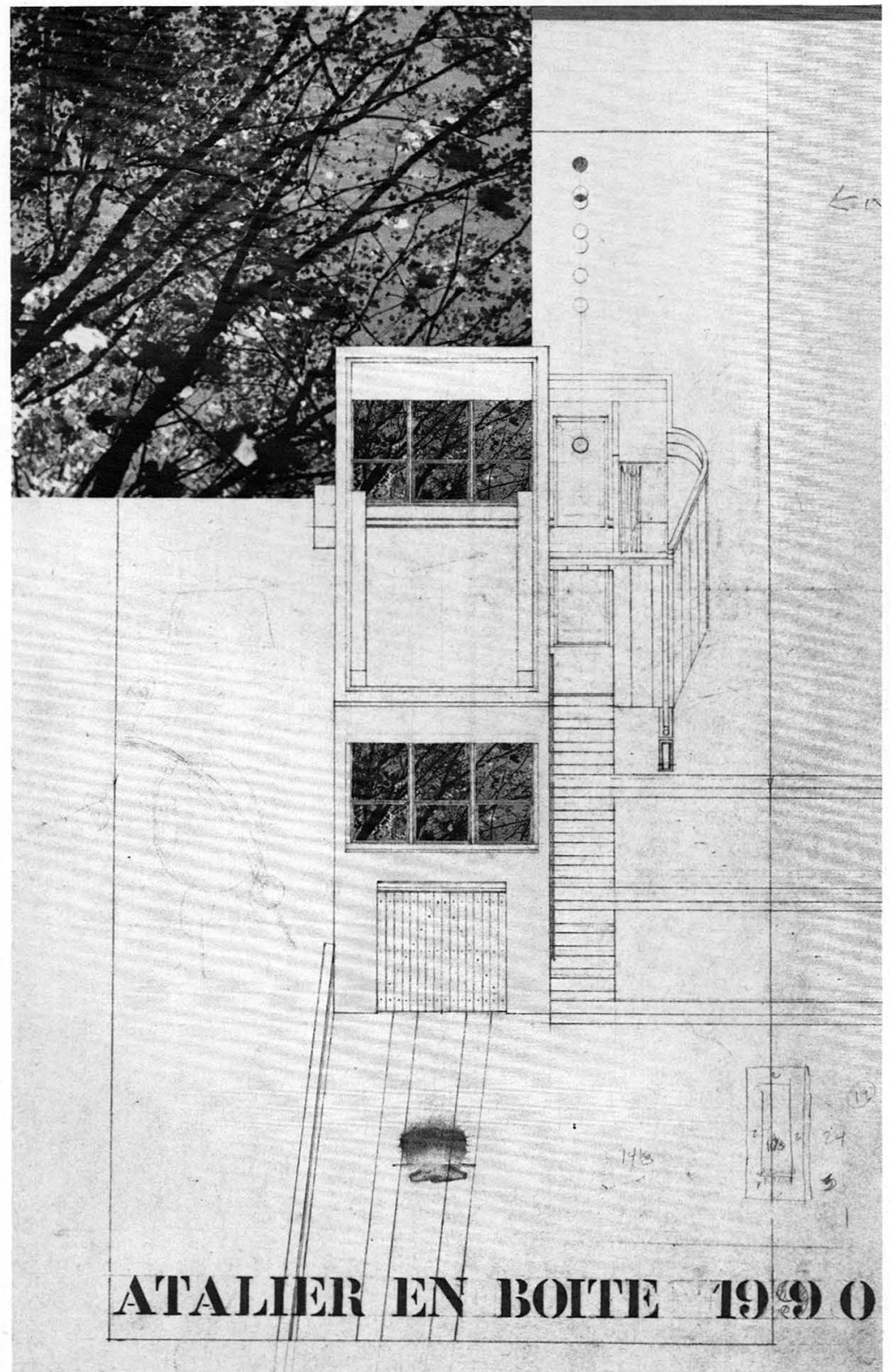

\section{PART I}

Good buildings like good pictures not only engage our eyes but also our mind. It is through the connection of sensory experience to thought, that craft is transformed into art, and building into architecture. When the builder/craftsman succeeds in making a thing which invites contemplation not only of itself but of the world at large, either by reference to natural law or to specific cultural conditions, its significance as an artifact of homo faber is greatly enhanced, and the alchemical transformation from utilitarian object to art-object is effected. Marcel Duchamp's readymades explicitly assert the alchemi$\mathrm{cal}$ power of the artist. By displaying a urinal, a snow shovel, etc., as art objects our reaction is changed from one of looking at the form of the object, to thinking about the larger frame: the art world and the meaning of art. Alberto Perez-Gomez has suggested that art is metaphysics made into matter. Similarly, art is matter dealing with metaphysics.

A brief analysis of Vermeer's The Artist in His Studio reveals the many levels of meaning operating simultaneously. It presents a picture of an artist painting a model. The unthinking eye recognizes this as the subject of the painting and accepts it as simply a realistic picture. Upon further investigation however one sees the very deliberate distinction made between two-dimensional representation and the three-dimensional world. The natural world is presented in the painting only in two-dimensional media; the flower-patterned curtain and the map on the wall. The real world's presence is made manifest in the light from an assumed window obscured from our view by the curtain. At approximately the center of the composition, and the center of the argument, the leaves on the model's head are the only unmediated piece of nature. And, it is precisely these leaves which appear on the painter's canvas suggesting that it is the representation in two-dimensions of the three-dimensional natural world which is indeed the subject of Vermeer's painting. ${ }^{1}$ To acknowledge the criticism that painting is a deceitful activity $^{2}$ Vermeer's paintings always self-reference to the representational act of painting itself and consequently to the natural world outside the painting. It is this engagement with ideas beyond the picture plane which distinguish art from illustration and the artist from the technician.

Architecture by necessity deals with many issues "beyond the picture plane". Programmatic, civic, and constructional needs are but a few of the requirements which good building must satisfy. But their satisfaction alone does not engage the mind or touch the heart, as Le Corbusier so eloquently put it.

My house is practical. I thank you, as I might thank Railway engineers or the Telephone service. You have not touched my heart. But suppose that walls rise towards heaven in such a way that I am moved. I perceive your intentions. ...You fix me to the place and my eyes regard 
it. They behold something which expresses a thought. A thought which reveals itself without word or sound, but solely by means of shapes which stand in a certain relationship to one another. These shapes are such that they are clearly revealed in light. The relationships between them have not necessarily any reference to what is practical or descriptive. They are a mathematical creation of your mind. They are the language of Architecture. By the use of inert materials and starting from conditions more or less utilitarian, you have established certain relationships which have aroused my emotions. This is Architecture. ${ }^{3}$

Suggested in this excerpt and elaborated on in many of Le Corbusier's later writings is the importance of mathematic relationships, (geometry and proportion), in elevating building to the status of architecture. Rudolf Wittkower has described the lineage of this idea:

There was an unbroken tradition coming down from antiquity according to which arithmetic, the study of numbers, geometry...the study of the motion of the celestial bodies, and music, the study of the motions apprehended by the ear formed the quadrivium of the mathematical 'arts'. By contrast to these 'liberal arts' painting, sculpture, and architecture were regarded as manual occupations. In order to raise them from the level of the mechanical to that of the liberal arts, they had to be given a firm, theoretical, that is to say, mathematical foundation. ${ }^{4}$

The idea that mathematics is able to theorize and explain the world has roots in Plato's distinction between removed world of essences and the tangible world of shadows. For Plato, ideal forms, (spheres, cubes, and other mathematically pure shapes) are able to reveal the essential nature of true reality. Similarly, in the Renaissance ideal shapes and ratios were held to reflect divine perfection; Leonardo's fascination with centrally-planned churches and Palladio's sequential room sizes based on musical harmonic progression are but two attempts through mathematics to relate the microcosm to the macrocosm and so increase the significance of building.

Le Corbusier secularized the same basic ides by emphasizing geometry and proportion's ability to relate part to whole. His diagram and discussions of proportion and formal structure suggest how correspondences can be established at the level of both detail to building and building to city, to culture, to nature. These nested correspondences extend the frame of the project and suggest the interrelatedness of all matter and action beyond simply ensuring the formal unity of the object.

Guarino Guarini in the seventeenth century also emphasized the transfunction of geometry. He believed that truth in all disciplines is accessed through the knowledge of relations. Geometry, therefore, as an ordering system of measurement and relational thinking links architecture to philosophy, astronomy, physics, theology, engineering and poetry. ${ }^{5}$ It is a sign of human intelligence and a means of relating various cultural endeavors as well as of mapping both heaven and earth. Geometry, like painting and philosophical writing, is a device used to translate three dimensions into two. It orders and rationalizes experience making the world intelligible.

Numerous other examples of the traditional intellectual importance associated with geometry and proportion in architecture could be mentioned. That the theoretical functions replaced by a strictly function-and engineering-oriented approach to number has been well documented by Alberto Perez-Gomez in $A r$ chitecture and the Crisis of Modern Science. He suggests that without a mathematical basis which is also transcendent and relates building to a larger frame of reference, architecture loses its metaphysical dimension, and remains at the level of mere building.

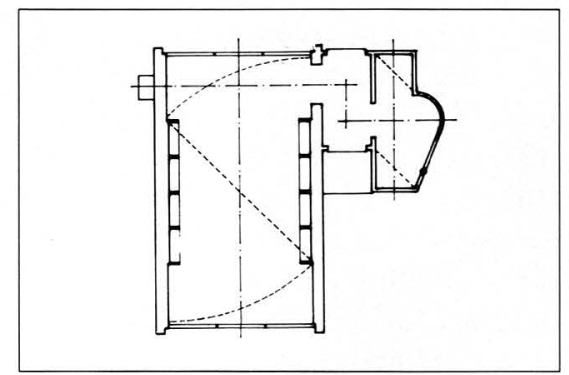

Plan Diagram

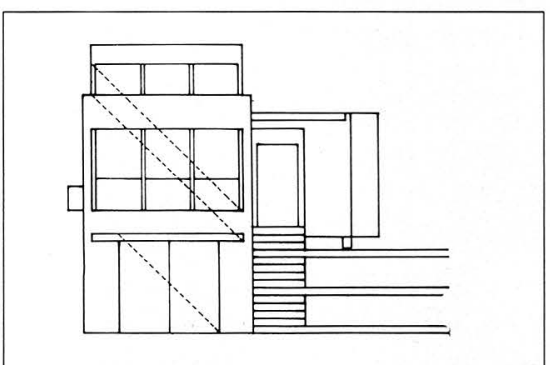

Elevation Diagram

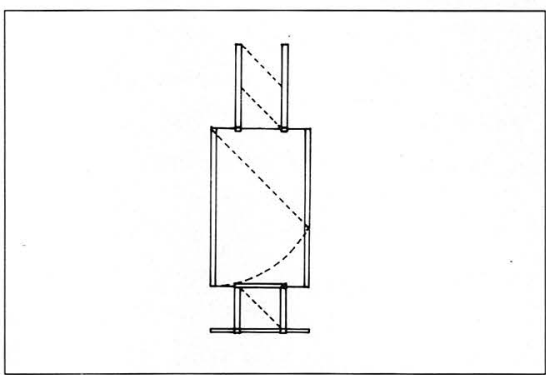

Suspended Bathroom Mirror

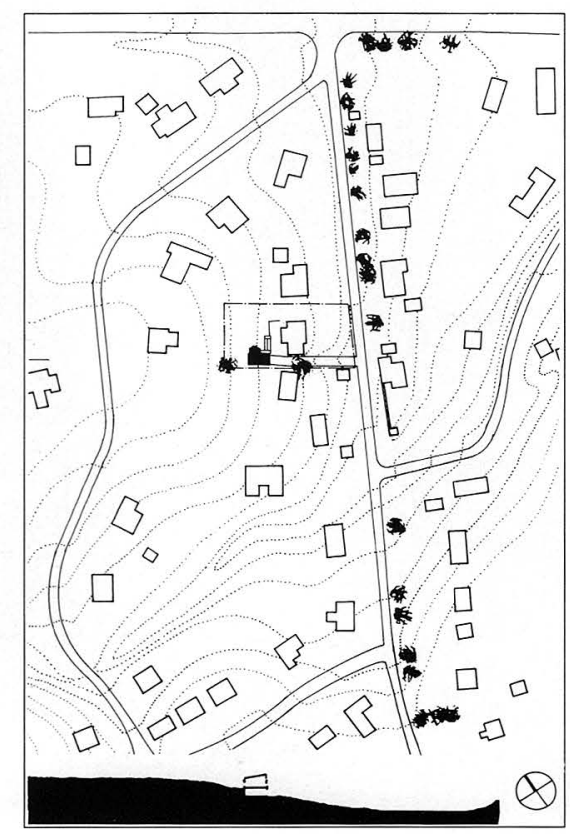

Location Plan

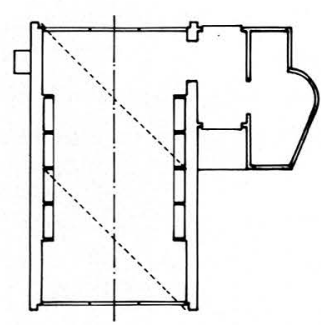

Plan Diagram

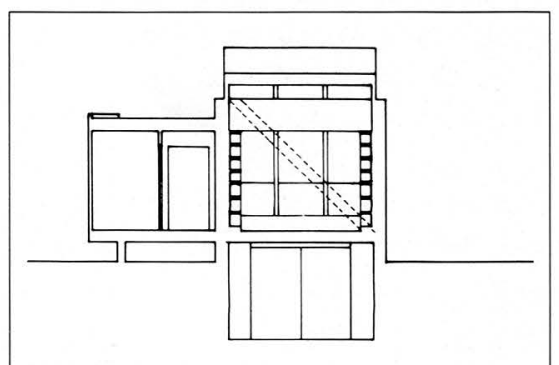

Section Diagram

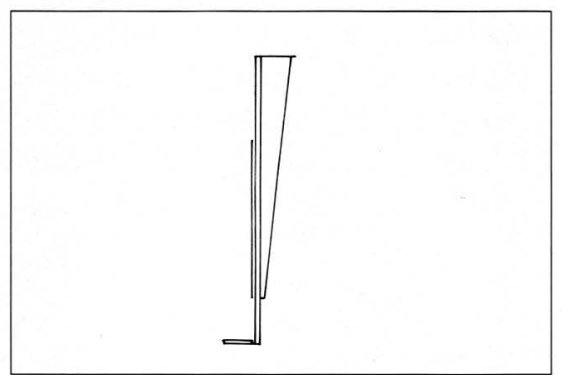

Suspended Bathroom Mirror

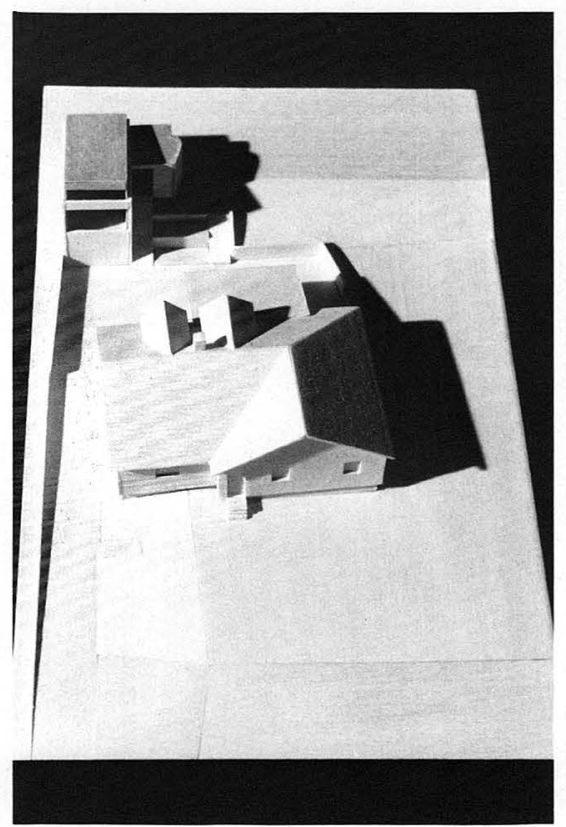

Site Model 


\section{PART II}

In the design of a small building in Charlottesville, Virginia for an astronomer and his musician wife, we tried to satisfy the requirements of good building as well as the intellectual dictates of considered architecture. In the spirit of Vermeer's self-consciousness about the primary conditions of painting, the Goldstein Studio is first and foremost a building which manipulates a spatial sequence and is about its construction. Only at the level of second order narratives do thematic ideas try to present the building as an object worthy of contemplation. Expanding on the issues of construction, site, and program given in the project, these ideas attempt to marry the physical and the metaphysical.

The project's program is very simple. It consists of a one-car garage, a bath, and a booklined room with near and distant views in which the client can continue his research in inter-stellar magnetism and the history of astronomy. These spaces are designed to enhance an existing sequence of outdoor spaces. The vertical face of the garage and studio terminate a relatively long and steep driveway while framing an outdoor street-like terrace off the rear of the main house. Projected into the rear yard, the more figural object of the entry-bath is hidden behind the body of the house until one arrives at the terrace. Inside the studio, the slope of the drive is spatially culminated and redirected under the reversed slope of the roof.

The form and many of the details of the building also try to work with existing conditions. The site sits on a hilly, narrow street of 1-2 acre residential lots surrounded by mature trees. A long row of tall cedar trees originally planted as fenceposts border the road and bear witness to the neighborhood's original configuration as a farm. A well-known loca architect, Milton Grigg, designed the earliest residences in the late nineteen-thirties picking up on the imagery and materials of the original farmhouse (across the street from the Goldstein's), and details of vernacular rural farmhouses in general. These include; additive compositions, the use of masonry and wood construction in close proximity, and detached outbuildings with barn doors. Desiring to complement the strong sense of place generated by these buildings, the Goldstein Studio was conceived as an elaborated outbuilding complete with a shed-roof and barn doors. It is also sited to be caught between two spectacular trees, in this case sugar maples. These trees are in turn framed by the studio's large windows and brought into the room through the use of maple flooring, bookcases and desktop.

Like its neighbors, the studio combines masonry and balloon frame construction. Concrete block foundations and walls sit the building in its sloped ground, while a wood stud inner liner in the studio periscopes up to the sky and provides a clerestory window. Completely above grade, the entry-and-bathroom pavilion is also wood frame construction. The tectonic logic of the construction is consistently expressed. All concrete block walls are finished in stucco while all wood construction is finished in standing seam terne metal. This contrast between heavy earthbound walls and reflective sloped or curved surfaces allows for a variety of readings: boxes in boxes, the planted box with machine extensions, (including the shiny metal automobile), and the condition of both architecture, agriculture and astronomer as mediating between earth and sky.

Another link between astronomy and architecture is geometry. It is used in the project to relate the module of construction - the 1:2 proportions of a concrete block-to the plan of the studio, (the length of the block walls is twice the width of the glass windows). Squares and diagonals are also employed throughout the project, at a variety of scales, as a means of further relating the various parts. The square figure formed by the clerestory and large window on the facade most

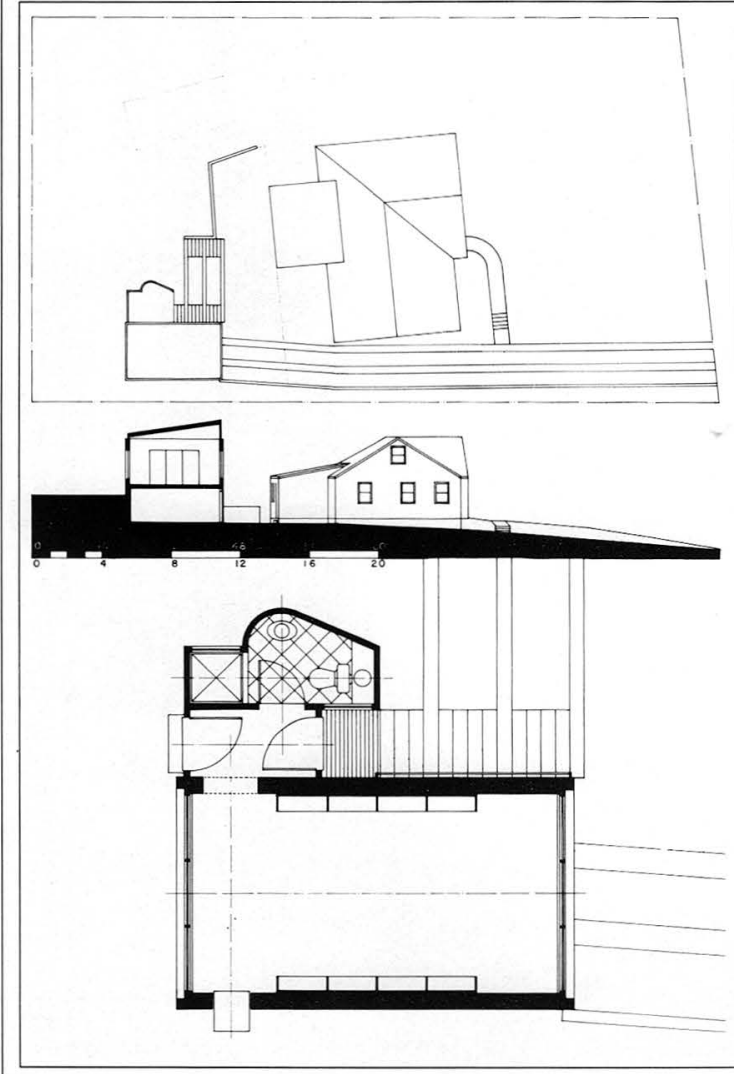

28

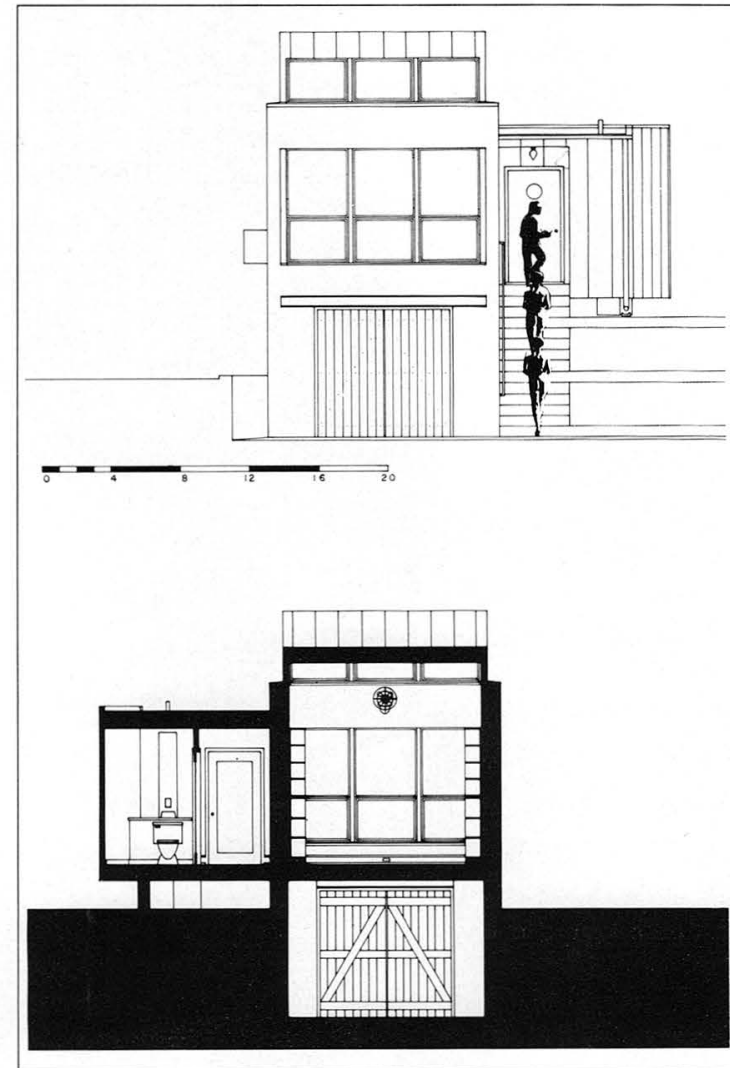

Front Elevation, Lateral Section

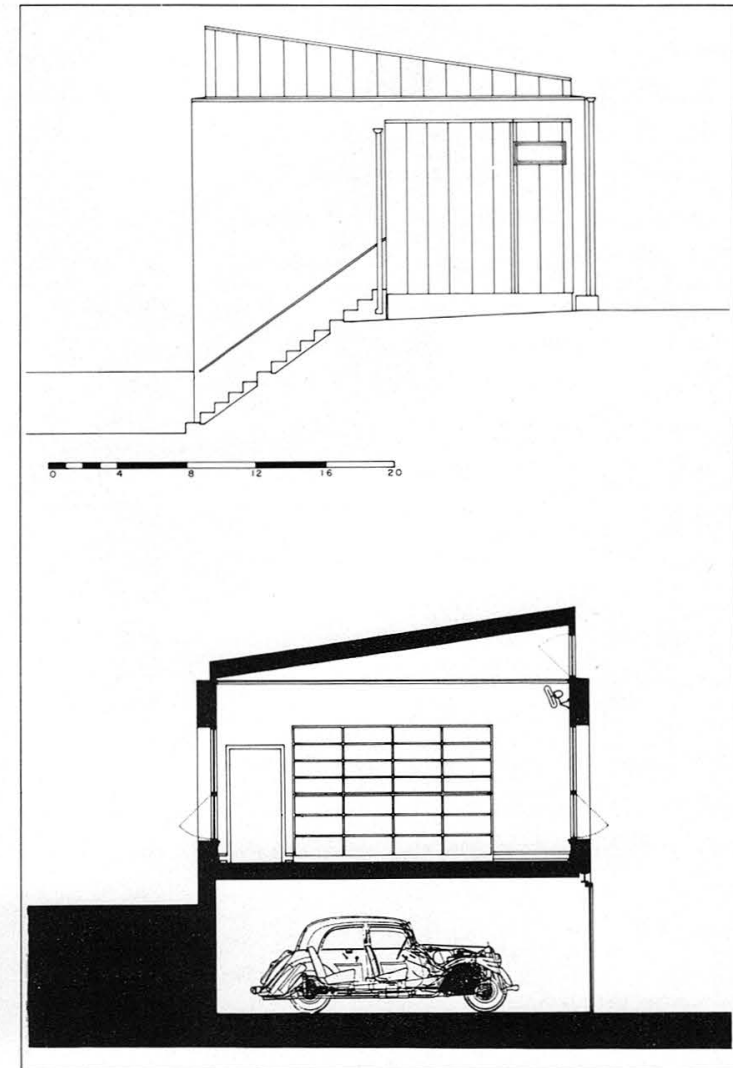

Side Elevation, Longitudinal Section 
directly associates geometry with the astronomer. By both enclosing him within the square and by framing his view of the world through this geometrically pure lens, the use of geometry as a means of measuring nature and understanding reality is suggested.

Vermeer presents this theme in his painting of the same subject, The Astronomer. Again, two-dimensional versus three-dimensional representation is a significant issue, here equated by the idea of mapping. We see the astronomer copying notes into a book while looking at a celestial globe in front of a gridded window. As the grid of the window maps the threedimensional world onto a two-dimensional surface, the astronomer's perceptions are transformed into conceptions recorded in the notebook. ${ }^{6}$ The mate to this painting is The Geographer. In it Vermeer again compares a gridded window to globe to a book, clearly intending to relate the mapping of topography and the necessity of each to other. To under- stand the position of the stars the astronomer must be well-grounded in knowledge of his place on the earth. The Goldstein Studio also tries to acknowledge the tension between being grounded in the immediate place while studying distant, timeless, abstractions of space. The Goldstein Studio attempts to ground the astronomer, both artist and scientist. The Goldstein Studio also incorporates Vermeer's distinction between perception and conception. The grid of windows is repeated in the grid of the bookcases. The literal view of the world is related to the conceptual view of the world through books. Observation is contrasted to reason as a form of knowledge. Formal contrasts heighten the tension of the distinction: deep/shallow, solid/void/, and transparent/opaque.

Other dualities in the project revolve around the identification of the studio with the mind, the bath with the body, and the garage with the machine. Again, a series of formal contrasts set these figures into various discursive oppositions: up/ down, light/dark, fixed/moving, deep/ shallow, diptych/triptych, and orthogonal/biomorphic. Form and program are brought together and overlaid with a rich series of metaphorical associations. These allow for constant re-reading and speculation. If the microcosm can still stand for the macrocosm, it is suggested that the world also needs constant re-reading and speculation.

Both the artist and the scientist seek to understand the nature of reality. The transformation of building into architecture requires participation in this search as well. To embark on such a project, architects need to aim at connecting the self to the physical and metaphysical world. In the end, we are satisfied that with the Goldstein Studio we at least made a good room and a large glass.
NOTES

1. Edward A Snow, A Study of Vermeer, University of California Press, Berkeley and Los Angeles CA 1979

2. Plato, from Part V, Book X "The Quarrel Between Philosophy and Poetry", in The Republic of Plato. Translated by Francis MacDonald Cornford, Oxford University Press, New York, 1968.

3. Le Corbusier, Towards a New Architecture, Translated by Frederick Etchells,Dover Publications, New York, 1968.

4. Rudolf Wittkower, Architectural Principles in theAge of Humanism, W.W. Norton \&Co., 1971

5. See Architecture and The Crisis of Modern Science by AlbertoPerez-Gomez, MIT Press, Cambridge Massachusetts, 1985, Chapter 3.

6. In the history of science it is Galileo, an astronomer, who is credited with first distinguishing the realms of perception and conception.

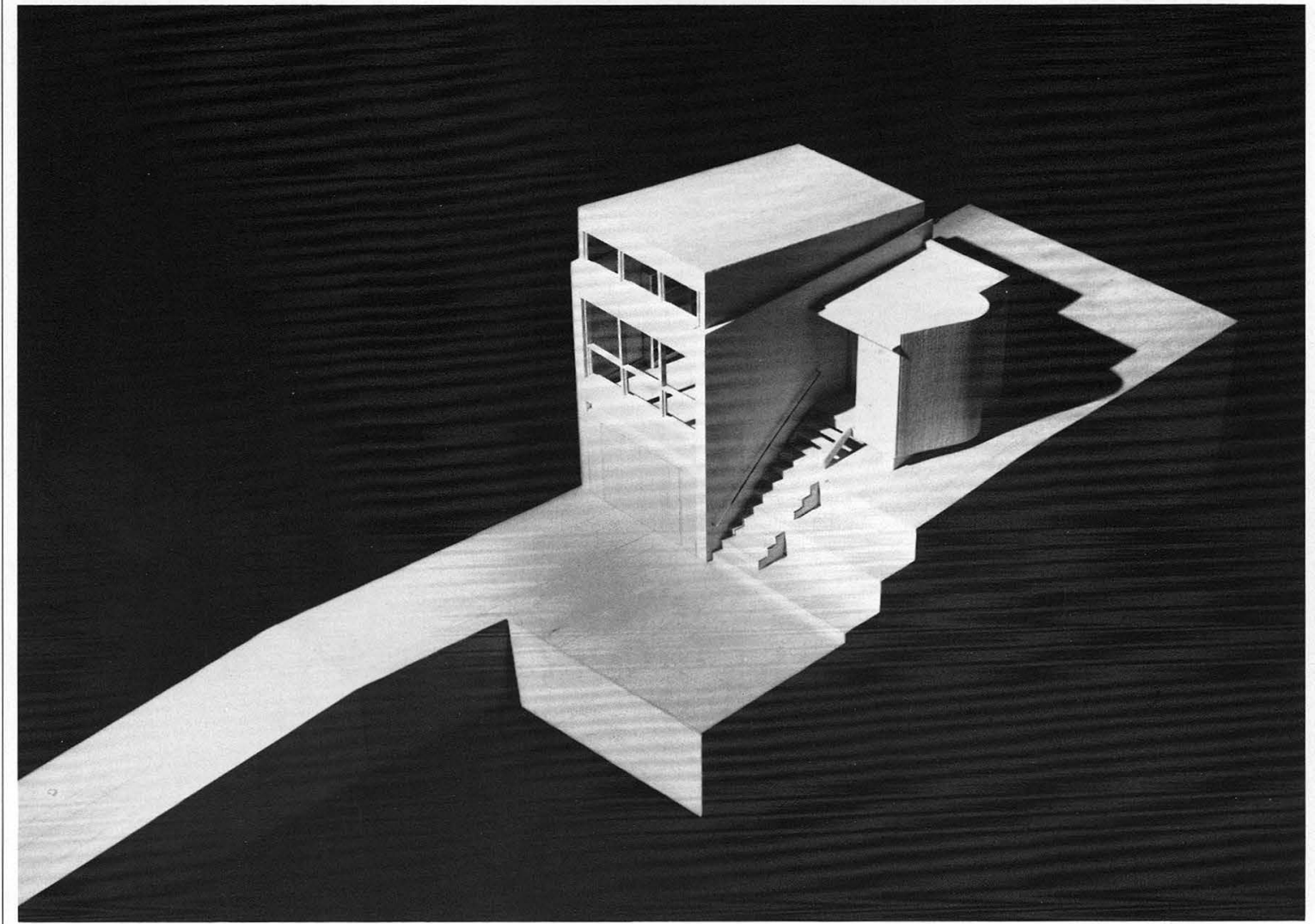

Model, View from Northwest

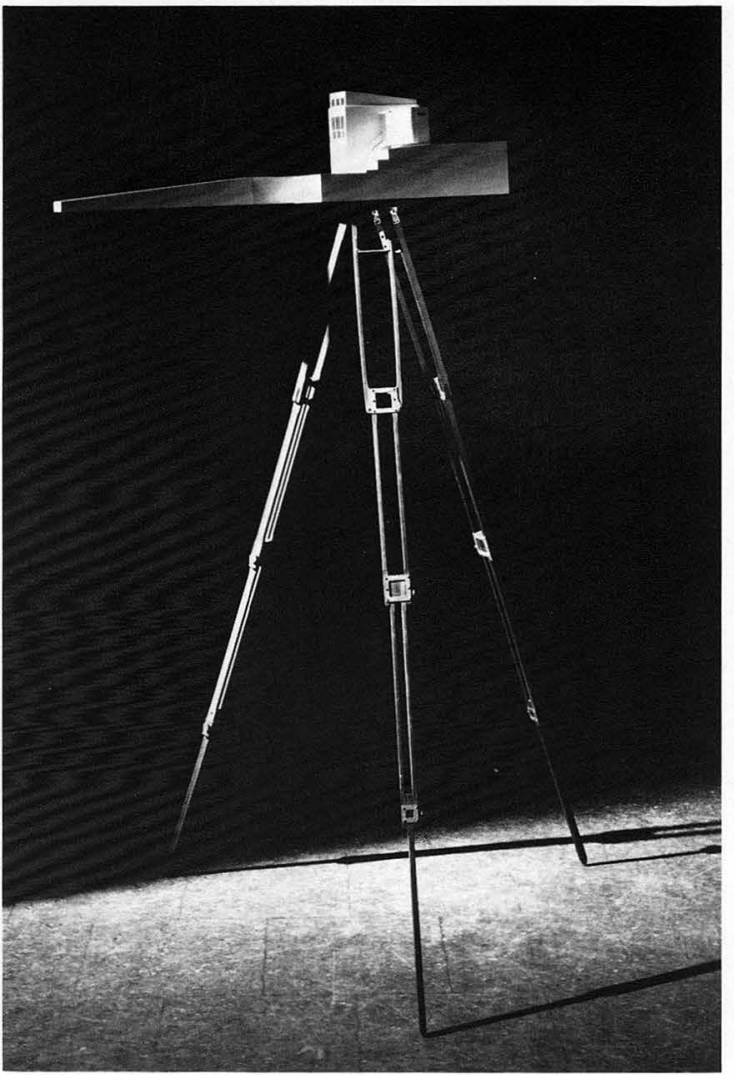

Goldstein Studio 